\title{
Sustentabilidade Empresarial e Governança Corporativa: Uma Análise da relação do ISE da BM\&FBOVESPA com a Compensação dos Gestores de Empresas Brasileiras
}

\begin{abstract}
Resumo
O objetivo deste artigo foi identificar a influência da sustentabilidade empresarial na compensação dos gestores das empresas brasileiras não financeiras da BM\&FBOVESPA de 2009 a 2013. Entende-se que o estudo da compensação dos gestores e da sustentabilidade empresarial proporciona reflexões sobre os problemas decorrentes da Teoria de Agência, bem como permite visualizar a teoria dos Stakeholders e a busca pelo valor em longo prazo. Para o desenvolvimento deste trabalho, espera-se que as empresas que estão listadas no Índice de Sustentabilidade Empresarial (ISE) da BM\&FBOVESPA concedam melhores remunerações a seus administradores. Dessa forma, foi utilizado o método de regressão com dados em painel, com estimação por efeitos fixos, com a finalidade de testar a relação existente entre as variáveis propostas. Como resultados principais, notou-se relação positiva e estatisticamente significativa da remuneração total dos gestores com o ISE, com a variável de qualidade da governança corporativa (empresas listadas no Novo Mercado) e com o valor de mercado (market-to-book). Ademais, observou-se uma relação negativa da remuneração total dos administradores com a volatilidade dos retornos. Desse modo, pode-se inferir que as empresas mais sustentáveis tendem a conceder maiores remunerações a seus gestores, o que corrobora a hipótese central da pesquisa e os pressupostos da teoria dos Stakeholders.
\end{abstract}

Palavras-chave: Sustentabilidade Empresarial. Governança Corporativa. Compensação dos Gestores. Teoria dos Stakeholders.

\begin{abstract}
Thayse Machado Guimarães Mestre em Administração pela Universidade Federal de Uberlândia (UFU) e Professora no Instituto Federal de Educação, Ciência e Tecnologia do Triângulo Mineiro (IFTM). Contato: Av. Líria Terezina Lassi Capuano, Chácara das Rosas, Patrocínio/MG, CEP: 38747-792. E-mail: thaysemg.adm@gmail.com
\end{abstract}

\section{Fernanda Maciel Peixoto} Doutora em Administração pela Universidade Federal de Minas Gerais (UFMG) e Professora na Universidade Federal de Uberlândia (UFU). Contato: Av João Naves de Ávila, 2121, Santa Mônica, Uberlândia/MG, CEP: 38400-902.

E-mail: fmacielpeixoto@gmail.com

\section{Luciana Carvalho}

Doutora em Economia pela Universidade Federal de Uberlândia (UFU) e Professora na Universidade Federal de Uberlândia (UFU). Contato: Av João Naves de Ávila, 2121, Santa Mônica, Uberlândia/MG, CEP: 38400-902

E-mail: lucarvalho@ufu.br 


\section{Introdução}

Em virtude das modificações percebidas no ambiente globalizado, cada vez mais as organizações buscam formas de se tornar mais competitivas e de alcançar, assim, melhor desempenho. Nesse sentido, destaca-se o papel do mercado de capitais como fonte de recursos que são convertidos em investimentos produtivos (Correia, 2008). A esse respeito, ressalta-se a importância da governança corporativa e da sustentabilidade empresarial como boas práticas, que tendem a proporcionar maior qualidade e perenidade dos negócios. Isso se justifica, pois a governança corporativa corresponde a um conjunto de relações entre a gestão da empresa, seu conselho de administração e demais stakeholders, tendo em vista o fornecimento de uma estrutura que possibilite às organizações alcançar eficiência econômica e possibilitar maior confiança aos investidores (OECD, 2004).

Sabe-se que a sustentabilidade empresarial, entendida como um conjunto de atividades que envolvem a relação da empresa com o ambiente, com a economia e com a sociedade, baseada no tripé de Elkington (2001), possibilita melhorias na imagem e reputação das empresas, captação vantajosa de recursos financeiros e maior vantagem competitiva (Garcia \& Orsato, 2013). Nesse sentido, entende-se que é fundamental que as empresas saibam definir sua função-objetivo para alcançarem seus propósitos. Por isso, Jensen (2001) apresenta como alternativa a teoria dos Stakeholders iluminada, segundo a qual as organizações precisam considerar os interesses essenciais de seus stakeholders, tendo em vista o objetivo de maximização de valor em longo prazo.

A preocupação com a conciliação dos diferentes interesses é refletida também na teoria de Agência. Por existir a inevitável separação entre propriedade e controle, as atividades de cooperação de indivíduos podem gerar conflitos (Jensen \& Meckling, 1976). Uma forma de solucionar esse conflito de agência estabelecido entre gestores e acionistas, de acordo com Murphy (1998), é conceder mecanismos de incentivo aos gestores, correspondentes a salários, planos de bônus anuais, plano de opção de compra de ações, entre outros. Assim, a riqueza de um executivo fica vinculada ao objetivo de maximização da riqueza dos acionistas.

No tocante à sustentabilidade empresarial, nota-se que ela geralmente é avaliada por índices de sustentabilidade das diferentes bolsas de valores mundiais. Esses índices seguem a proposta de Elkington (2001). Desse modo, destacam-se os índices Dow Jones Sustainability Index (DJSI) dos Estados Unidos; o FTSE4Good, em Londres; o JSE em Joanesburgo, na África do Sul; e o Índice de Sustentabilidade Empresarial (ISE), no Brasil. O ISE da BM\&FBOVESPA tem por objetivo proporcionar um ambiente de investimentos compatível com as demandas do desenvolvimento sustentável da sociedade contemporânea.

Assim como afirmam Ricart, Rodriguez e Sanchez (2005), muitas pesquisas de cunho teórico envolvem os temas Governança Corporativa e Desenvolvimento Sustentável, mas não foi encontrado nenhum trabalho empírico que trate da relação entre esses temas. Ademais, ao se considerarem os diferentes mecanismos de governança corporativa, como, por exemplo, conselho de administração; estrutura de propriedade e controle; proteção aos acionistas minoritários; transparência; e compensação dos gestores, não foram encontrados estudos que testassem a relação de algum deles (ou de todos) com os índices de sustentabilidade empresarial.

Tendo em vista essa lacuna observada na literatura sobre o tema, o problema de pesquisa deste estudo é: qual é a influência da sustentabilidade empresarial na compensação dos gestores das empresas brasileiras não financeiras da BM\&FBOVESPA? Com base nessas perspectivas, este estudo apresenta como hipótese: $\mathrm{H}_{1}$ - As empresas listadas no ISE da BM\&FBOVESPA concedem maiores compensações aos seus gestores. Assim, diante do problema de pesquisa e da hipótese apresentada, o objetivo deste estudo é investigar a influência da sustentabilidade empresarial na compensação dos gestores das empresas brasileiras não financeiras da BM\&FBOVESPA no período de 2009 a 2013. 
Ressalta-se que este trabalho apresenta contribuições de cunho teórico, visto que propõe a análise da relação da sustentabilidade empresarial com a compensação dos gestores, relação essa que envolve, respectivamente, os temas Sustentabilidade e Governança Corporativa, que anteriormente não haviam sido considerados sob este enfoque. Soma-se a isso a contribuição prática do trabalho, pois pretende-se avaliar se as empresas mais sustentáveis, as quais buscam a geração de valor em longo prazo, também almejam o alinhamento de interesses dos diferentes stakeholders (sendo neste caso, gestores e acionistas), por meio de maiores compensações aos seus gestores.

Esta pesquisa está estruturada em cinco seções, das quais esta seção envolve o problema de pesquisa, a hipótese e os objetivos. A seção 2 apresenta a estrutura teórica, a seção 3 os aspectos metodológicos do estudo, as variáveis analisadas, os métodos utilizados na análise estatística, bem como o modelo estimado na pesquisa. Já a seção 4 traz a apresentação e análise dos resultados e, na seção 5 , são formuladas as conclusões resultantes da análise da fundamentação teórica sobre os principais temas abordados e dos tratamentos empíricos realizados.

\section{Referencial Teórico}

\subsection{A Compensação dos Gestores}

Para compreender o surgimento das boas práticas de governança corporativa, que envolvem os mecanismos de Governança Corporativa, dentre os quais este trabalho foca na análise da compensação dos gestores, é preciso, primeiramente, compreender o surgimento da teoria de Agência. Jensen e Meckling (1976) afirmam que o estabelecimento de contratos faz com que o agente se empenhe em realizar atividades para o principal, enquanto este se compromete em remunerar o agente. No entanto, por haver a inevitável separação entre propriedade e controle, as atividades dos indivíduos são suscetíveis de diversos tipos de conflitos, os quais foram denominados de "Conflitos de Agência".

Mesmo que os Conflitos de Agência sejam diferentes entre os países, observa-se que a governança corporativa tem buscado melhorar a transparência; reforçar o monitoramento independente da gestão, o alinhamento entre os principais e os agentes, os direitos dos acionistas; e impor responsabilidades financeiras aos agentes e administradores (Wong, 2009). Assim, é possível destacar, no caso brasileiro, os seguintes mecanismos de governança corporativa: conselho de administração; estrutura de propriedade e controle; proteção aos acionistas minoritários; transparência das informações publicadas; e compensação dos gestores (Correia, 2008). Entre os mecanismos citados, a compensação dos gestores corresponde a uma das formas de solucionar o Conflito de Agência comentado, visto que, assim como afirma Murphy (1998), a riqueza de um executivo está ligada ao objetivo de maximização da riqueza dos acionistas.

Um dos trabalhos seminais a esse respeito é o de Jensen e Murphy (1990), que buscaram evidenciar a forma como os executivos têm sido pagos e observaram que, em média, os pagamentos não são realizados com base na performance das empresas e a política de remuneração é um dos fatores mais importantes para o sucesso das organizações, já que, além de estar relacionada ao comportamento dos executivos, também determina o tipo de executivo que é atraído pelas companhias. Sendo assim, destacam-se três políticas básicas que possibilitam aos Chief Executive Officer (CEOs) maximizar o valor das companhias: a) permitir que os executivos sejam proprietários substanciais; b) estruturar os salários, bônus e opções de compra de ações para gerar grandes recompensas quando há desempenho superior e punições para o mau desempenho; e c) utilizar a ameaça demissional em caso de desempenho ruim (Jensen \& Murphy, 1990). 
Na literatura internacional e nacional, embora tenha sido observado que as organizações que apresentam melhor performance garantem melhores compensações a seus executivos (Barontini \& Bozzi, 2008; Conyon \& He, 2011; Kaplan, 2012; Kaplan \& Rauh, 2009; Suherman, Rahmawati \& Buchdadi, 2011), constatou-se, também, a relação contrária, ou seja, situações em que as variáveis de compensação apresentaram relação negativa com a performance organizacional (Balafas \& Florackis, 2013; Beuren \& Beck; Silva, 2012). Por isso, não se pode inferir que o fato de a empresa apresentar boa performance seja a garantia de maiores compensações a seus gestores e vice-versa.

De maneira complementar, Conyon e He (2011) analisaram as companhias de capital aberto na China durante o período de 2001 a 2005. Os resultados mostraram que a compensação dos executivos, medida pelo logaritmo da remuneração total (salários e benefícios), apresentou relação positiva com a performance das empresas, sendo esta medida pelo retorno das ações, nos últimos doze meses, e também pelo Retorno sobre o Ativo Total (ROA). Houve maior relação entre o pagamento dos gestores e a performance das organizações nas empresas com conselheiros independentes e, nas empresas controladas pelo Estado e que tinham propriedade concentrada, os incentivos foram menores.

Assim como observado nos estudos internacionais, alguns pesquisadores brasileiros buscaram compreender a influência de características da governança corporativa na remuneração dos executivos. Vale ressaltar que a maioria das pesquisas apresentam resultados que comprovam uma relação positiva e estatisticamente significativa entre estas variáveis (Camargos \& Helal, 2007; Correia, Amaral \& Louvet, 2014; Farias, 2012; Pinto \& Leal, 2013; Silva, 2010; Victor \& Terra, 2009), mas há evidências de que nem sempre a governança corporativa influencia positivamente os benefícios dos administradores (Funchal \& Terra, 2006; Sampaio, 2009).

Geralmente as pesquisas brasileiras sobre este tema investigam como o desempenho corporativo influencia os benefícios pagos aos administradores (Beuren, Beck \& Silva, 2012; Camargos \& Helal, 2007; Dalmacio, Rezende \& Slomski, 2009; Funchal \& Terra, 2006) e como a compensação dos gestores impacta no valor de mercado ou no desempenho contábil das empresas (Carvalhal da Silva \& Chien, 2013; Krauter, 2013; Perobelli, Lopes \& Silveira, 2012; Sampaio, 2009; Sonza, 2012).

Especialmente, Funchal e Terra (2006) consideraram uma amostra composta por 67 empresas de quatro países (Argentina, Brasil, Chile e México) no ano de 2002 e utilizaram a análise de regressão cross-section. Desse modo, notaram que o desempenho da empresa, expresso pelo valor de mercado e pelo $Q$ de Tobin e a governança corporativa não são variáveis influentes na remuneração executiva, a qual foi medida pelo logaritmo da remuneração total (salários e benefícios). No entanto, encontraram relação positiva e significativa entre o tamanho da empresa e a compensação dos gestores, o que leva à conclusão de que, em empresas maiores, os executivos tendem a ser melhor remunerados.

\subsection{A Sustentabilidade Empresarial}

Com a finalidade de se compreender a sustentabilidade empresarial, parte-se, à princípio, da interpretação da teoria dos Stakeholders. Segundo os autores Freeman e McVea (2001), os gestores formulam e implementam suas estratégias visando à satisfação de seus stakeholders, em vez de maximizarem os direitos de um único grupo em detrimento dos demais. No entanto, Jensen (2001) propõe que as organizações atendam às demandas mais relevantes das partes interessadas, mas que tenham como função-objetivo a maximização de valor em longo-prazo. Nesse contexto, visualiza-se a sustentabilidade empresarial, que envolve as frentes econômica, social e ambiental. Assim, entende-se que a sustentabilidade empresarial abrange um conjunto de práticas economicamente viáveis, socialmente justas e ecologicamente corretas (Elkington, 2001). 
O desenvolvimento da sustentabilidade empresarial está associado às mudanças observadas no mercado de capitais, em virtude da maior democratização e transparência na circulação de informações (Henderson, 2007). Alguns fatos históricos marcaram essa evolução, com especial destaque para algumas catástrofes como a de Bhopal na Índia, em 1984, e o acidente nuclear de Chernobyl, em 1986, na Europa. Posteriormente a episódios como esses, foi formulado o Relatório de Brundtland, em 1988, o qual lançava conceitos de sustentabilidade, alterando, assim, algumas práticas de negócios no mundo.

Como consequência de mais escândalos mundiais, como o colapso de grupos econômicos (Enron, Union Carbide, WorldCom e Tyco), os investidores começaram a desconfiar da efetividade dos resultados financeiros (ISE, 2010). Desse modo, a partir da criação do DJSI, outros índices surgiram, sendo eles: FTSE4Good, criado em Londres no ano de 2001; JSE, criado em Joanesburgo na África do Sul em 2003; e o ISE, criado em 2005 no Brasil. O ISE funciona como uma ferramenta para análise comparativa da performance das empresas listadas na BM\&FBOVESPA, sob o aspecto de sustentabilidade empresarial, e mede o retorno médio de uma carteira teórica de ações de empresas de capital aberto, sendo a carteira formada por no máximo 40 empresas.

Para integrar o ISE, é necessário que as ações atendam, cumulativamente, aos seguintes critérios: a) ser uma das ações com maior índice de negociabilidade, apurados nos doze meses anteriores ao início do processo de reavaliação; b) ter sido negociada em pelo menos $50 \%$ dos pregões ocorridos nos doze meses anteriores ao início do processo de reavaliação; e c) atender aos critérios de sustentabilidade referendados pelo Conselho do ISE (ISE, 2010). A metodologia de avaliação é baseada em um questionário, que contempla sete dimensões: natureza do produto; geral; governança corporativa; social; econômico-financeira; ambiental; e mudanças climáticas. Cada uma dessas dimensões possui os seus critérios específicos de avaliação, de forma que o ISE seja mais do que um indicador de retorno financeiro, isto é, seja capaz de traduzir uma gestão sustentável.

Destaca-se que muitas pesquisas brasileiras sobre sustentabilidade empresarial, adotam como variável o ISE da BM\&FBOVESPA. Em algumas delas foi possível observar que melhores práticas de sustentabilidade estão associadas a melhor desempenho contábil (Lameira, Ness Jr., Quelhas \& Pereira, 2013; Nunes, Teixeira, Nossa \& Galdi, 2010), geralmente medido pelo ROA; maiores valores de mercado (Carvalhal \& Tavares, 2013; Lameira et al., 2013; Rossi Jr., 2009), na maioria das vezes expresso pelo Market-to-Book (MTB), maior potencial de vendas e exportação (Vital, Cavalcante, Dallo, Moritz \& Costa, 2009) e maiores retornos das ações (Alves, 2008; Beato, Souza \& Parisotto, 2009).

Entretanto, não há um consenso a respeito dos investimentos em sustentabilidade, visto que há casos em que as organizações que não fazem parte do ISE apresentam melhores indicadores de performance financeira (Vital et al., 2009) ou situações em que os investimentos socialmente responsáveis apresentam retornos semelhantes aos dos outros índices da BM\&FBOVESPA (Machado, Machado \& Corrar, 2009).

Vale destacar que investir em um índice de sustentabilidade, como o ISE, pode proporcionar menor risco aos investidores (Espejo, 2008; Lameira et al., 2013; Teixeira, Nossa \& Funchal, 2011), sendo o risco geralmente avaliado pela volatilidade dos retornos, ou não proporcionar vantagem nenhuma quanto à minimização do risco (Cavalcanti \& Boente, 2011; Nunes et al., 2010). Ademais, foi comprovado que investir no ISE pode garantir menor endividamento (Teixeira, Nossa \& Funchal, 2011) e maior disclosure social e ambiental (Holanda \& Mapurunga, 2012; Milani Filho, 2008).

\subsection{Sustentabilidade e Governança Corporativa}

Geralmente, os trabalhos sobre governança corporativa e sustentabilidade empresarial buscam investigar se investir em estratégias mais sustentáveis e que promovam maior qualidade da governança geram algum impacto na performance das organizações, sendo essa medida pelo desempenho contábil - ROA (Funchal \& Terra, 2006; Carvalhal da Silva \& Chien, 2013; Lameira et al, 2013), pelo retorno das ações, valor de mercado - MTB (Carvalhal da Silva \& Chien, 2013), bem como o risco - volatilidade dos retornos das ações (Carvalhal da Silva \& Chien, 2013; Carvalhal \& Tavares, 2013). As pesquisas que abordam esses temas conjuntamente buscam propor modelos teóricos que vinculem essas duas perspectivas. 
Em relação ao estudo de Sprague (2010), nota-se que o autor apresenta a perspectiva dos temas governança corporativa e sustentabilidade empresarial, além do valor da empresa, ou seja, do valor gerado ao acionista. O trabalho corrobora os estudos de Jensen (2001), por sustentar que as organizações, que desejam garantir valor no longo prazo, precisam considerar o relacionamento com os stakeholders, em vez de, simplesmente, evidenciarem a busca pelo lucro. Ademais, esse autor apresenta que, em épocas de crise, como a crise financeira de 2008-2009, as doutrinas que enfatizam o acionista e o autointeresse levaram muitas empresas ao fracasso em seu mercado.

Mason e Simmons (2014), por sua vez, afirmam que uma auditoria, baseada na responsabilidade social corporativa, pode avaliar os sistemas de governança corporativa, atendendo, então, aos interesses dos Stakeholders. Nesse sentido, eles propuseram um modelo em que a governança corporativa incorpora a responsabilidade social corporativa. Esse modelo foi fundamentado na teoria dos Stakeholders e envolveu questões como poder, eficácia e equidade.

Essa integração também foi observada na pesquisa de Krechovská e Procházková (2014), os quais investigaram 193 empresas da República Checa, de pequeno, médio e grande porte. Eles verificaram que as empresas estão cientes da importância da sustentabilidade para a geração de valor em longo prazo. De maneira complementar, notaram que muitas companhias não utilizam a sustentabilidade como uma estratégia corporativa e não a incluem nas medidas de performance gerencial.

Segundo esses autores, a governança corporativa deve, primeiramente, envolver a sustentabilidade, de modo que as empresas cumpram os princípios sustentáveis, o que corrobora os estudos de Mason e Simmons (2014). Desse modo, afirmam que, se a sustentabilidade não for incluída na formulação dos objetivos, das estratégias corporativas e das políticas e processos (desde o topo), os esforços das companhias para serem sustentáveis se tornam desnecessários.

Percebe-se, portanto, uma escassez na literatura tanto nacional como internacional sobre pesquisas que tratem desses dois temas de forma integrada. Destaca-se também a ausência de estudos empíricos sobre governança e sustentabilidade, o que justifica o presente estudo, mostrando seu diferencial perante os demais autores.

\section{Metodologia da Pesquisa}

\subsection{Amostra e dados}

Este estudo classifica-se como descritivo, quantitativo, documental e de levantamento. Foram utilizados dados secundários de diferentes fontes, sendo elas: (i) Formulário de Referência da Comissão de Valores Mobiliários (CVM) e Relatório 20-F da Securities and Exchange Commssion (SEC) para obtenção da remuneração total dos gestores; (ii) Carteiras do ISE da BM\&FBOVESPA para identificação das empresas listadas ou não no ISE; (iii) Carteiras do Índice de Governança Corporativa (IGC) da BM\&FBOVESPA para identificação das empresas listadas no Novo Mercado; e (iv) Economática para obtenção das variáveis de controle.

A amostra contemplou as empresas abertas não financeiras listadas na BM\&FBOVESPA, no período de 2009 a 2013, e que apresentaram liquidez de $0,001 \%$ do índice correspondente à companhia que teve as ações mais liquidas em 50\% ou mais dos anos da pesquisa, tendo como referência o ano de 2013. Essa metodologia foi proposta por Silveira (2004). O ano de 2009 foi definido como o início do período amostral, pois, anteriormente, poucas empresas divulgavam a remuneração fixa e variável da diretoria e do conselho de administração separadamente. Foi, portanto, a promulgação da Instrução CVM no 480 , em 2009, que obrigou as organizações de capital aberto a apresentar informações detalhadas sobre a remuneração dos administradores no formulário de referência (Carvalhal da Silva \& Chien, 2013). Desse modo, a amostra considerada envolveu 236 empresas listadas na BM\&FBOVESPA, compondo um painel desbalanceado, ou seja, para algumas empresas há dados somente em parte do período amostral. 


\subsection{Modelo de regressão com dados em painel}

Este estudo contempla dados de corte transversal (i) relacionados com as características das organizações ao longo de uma série temporal (t) de 2009 a 2013, envolvendo tanto uma dimensão espacial quanto temporal. Desse modo, os modelos estatísticos mais adequados são de regressões de dados em painel (Greene, 2002).

Os modelos em painel tratam a heterogeneidade dos dados e são divididos em modelos de efeitos fixos e de efeitos aleatórios. Para analisar a especificação mais adequada, procedeu-se, primeiramente, ao teste de Lagrange Multiplier (LM), proposto por Breusch e Pagan (1980), que testa a hipótese nula dos efeitos individuais não observáveis serem relevantes para a explicação do modelo e permite decidir entre os modelos pooled e o de efeitos aleatórios. Posteriormente, foi realizado o teste de Hausman, que avalia a correlação entre e os efeitos individuais do intercepto, sob a hipótese nula de $\operatorname{corr}()=0$. Desse modo, se os efeitos do intercepto não forem correlacionados com os, opta-se pelo modelo de Efeitos Aleatórios, mas se houver correlação, escolhe-se o modelo de Efeitos Fixos.

Ademais foram realizados o teste de Heterocedasticidade, de Baum (2001); o teste de Autocorrelação, de Wooldridge (2002); e o teste de Multicolinearidade, que avalia a existência de relação linear entre as variáveis (Gujarati \& Porter, 2011). Em suma, para avaliar a relação entre a sustentabilidade empresarial e a compensação dos gestores, utilizaram-se os modelos de Conyon e He (2011) e de Funchal e Terra (2006). Estes autores investigaram algumas variáveis que podem influenciar na compensação dos gestores, mas não consideraram a sustentabilidade empresarial. Logo, este estudo inova ao acrescentar esse último aspecto. Ressalta-se que foi utilizado o software Stata 11 para os testes do modelo estimado, descrito abaixo:

$$
\mathrm{RT}_{\mathrm{it}}=\beta_{0}+\beta_{1} \mathrm{ISE}_{\mathrm{it}}+\beta_{\mathrm{n}} \mathrm{VC}_{\mathrm{it}}+\varepsilon_{\mathrm{it}}
$$

Em que,

$\mathrm{i}=$ indicador cross-section;

$\mathrm{t}=$ indicador de tempo;

$\mathrm{n}$ = representa o número de variáveis de controle da equação;

$\beta=$ coeficientes associados às variáveis independentes e de controle;

$\mathrm{RT}=$ remuneração total dos gestores;

ISE = variável independente de sustentabilidade empresarial;

$\mathrm{VC}=$ variáveis de controle da equação; e

$\varepsilon=$ termo de erro da equação.

O quadro 1 apresenta a variável dependente, bem como a variável independente (Sustentabilidade Empresarial) e as variáveis de controle conforme os modelos considerados. 
Quadro 1

Variáveis da pesquisa - modelo Compensação dos Gestores e ISE

\begin{tabular}{|c|c|c|c|c|}
\hline \multicolumn{5}{|c|}{ Variável Dependente de Teste } \\
\hline Var. & $\begin{array}{c}\text { Sinal } \\
\text { Esperado }\end{array}$ & Descrição & Definição Operacional & Autores \\
\hline RT & & $\begin{array}{l}\text { Remuneração } \\
\text { total executivos }\end{array}$ & $\begin{array}{l}\text { In (salário base }+ \text { bônus + } \\
\text { outros benefícios) }\end{array}$ & $\begin{array}{l}\text { Barontini e Bozzi (2008), Conyon e He } \\
\text { (2011) e Funchal e Terra (2006) }\end{array}$ \\
\hline \multicolumn{5}{|c|}{ Variável Independente de Teste } \\
\hline ISE & $(+/-)$ & ISE & $\begin{array}{c}\text { Dummy } 0 \text { e } 1 \text { se as empresas } \\
\text { estão listadas no ISE da } \\
\text { BM\&FBOVESPA }\end{array}$ & $\begin{array}{c}\text { Alves (2008), Beato, Souza e Parisotto } \\
\text { (2009), Carvalhal e Tavares (2013), } \\
\text { Lameira et al. (2013), Machado, Machado } \\
\text { e Corrar (2009), Rossi Jr (2009) e Vital et al } \\
\text { (2009) }\end{array}$ \\
\hline \multicolumn{5}{|c|}{ Variáveis de Controle } \\
\hline NM & $(+)$ & $\begin{array}{l}\text { Participação no } \\
\text { Novo Mercado }\end{array}$ & $\begin{array}{l}\text { Dummy } 1 \text { para empresas } \\
\text { listadas no Novo Mercado e } \\
0 \text { para as que estão listadas } \\
\text { nos outros níveis e no } \\
\text { mercado tradicional. }\end{array}$ & Carvalhal da Silva e Chien (2013) \\
\hline ROA & $(+)$ & $\begin{array}{l}\text { Retorno sobre } \\
\text { o Ativo Total }\end{array}$ & $\mathrm{ROA}=\frac{\text { Lucro Líquido }}{\text { Ativo Total }}$ & $\begin{array}{l}\text { Carvalhal da Silva e Chien (2013), Funchal } \\
\text { e Terra (2006) e Lameira et al. (2013). }\end{array}$ \\
\hline VOL & $(+)$ & $\begin{array}{l}\text { Volatilidade dos } \\
\text { Retornos }\end{array}$ & $\mathrm{VOL}=\sigma\left(\ln \left(\frac{\mathrm{P}_{\mathrm{t}}}{\mathrm{P}_{\mathrm{t}-1}}\right)\right)$ & $\begin{array}{l}\text { Carvalhal da Silva e Chien (2013) e } \\
\quad \text { Carvalhal e Tavares (2013) }\end{array}$ \\
\hline CRESC & $(+)$ & $\begin{array}{l}\text { Oportunidades } \\
\text { de Crescimento }\end{array}$ & $\begin{array}{l}\% \text { de aumento da receita } \\
\text { líquida a cada três anos }\end{array}$ & Carvalhal da Silva e Chien (2013) \\
\hline MTB & $(+)$ & Market-to-Book & MTB $=\frac{\text { Valor de Mercado }}{\text { Ativo Total }}$ & Carvalhal da Silva e Chien (2013) \\
\hline TAM & $(+/-)$ & $\begin{array}{l}\text { Tamanho da } \\
\text { empresa }\end{array}$ & Ln (Total Ativos) & $\begin{array}{l}\text { Carvalhal da Silva e Chien (2013), Funchal } \\
\text { e Terra (2006) e Lameira et al. (2013) }\end{array}$ \\
\hline
\end{tabular}

Fonte: Elaborado pelos autores.

Após o delineamento da pesquisa, amostra, dados, método de regressão e seleção das variáveis para os modelos econométricos, passou-se à análise dos resultados empíricos deste estudo.

\section{Resultados e discussão}

\subsection{Estatística descritiva}

A Tabela 1 apresenta as estatísticas descritivas das variáveis deste estudo. Em média, a remuneração total dos gestores foi de $\mathrm{R} \$ 8,48$ milhões. O desvio-padrão foi de $\$ 10,76$ milhões, o que indica grande dispersão dessa variável, com a maior remuneração total dos gestores correspondente a $R \$ 117,10$ milhões.

Em relação à variável ISE, observa-se que, aproximadamente, 13\% da amostra é composta por empresas listadas no índice de sustentabilidade da BM\&FBOVESPA. Essa representatividade se justifica, pois as carteiras anuais do ISE são formadas por, no máximo, 40 empresas. Além disso, cerca de $49 \%$ das empresas analisadas fazem parte do Novo Mercado. 
Tabela 1:

Estatística descritiva das variáveis utilizadas no estudo

\begin{tabular}{cccccc}
\hline & N. Obs & Média & Desvio Padrão & Máx & Min \\
\hline RT & 1024 & 8,48 & 10,76 & 117,10 & 0,00 \\
\hline ISE & 1076 & 0,13 & 0,33 & 1,00 & 0,00 \\
\hline NM & 1076 & 0,49 & 0,50 & 1,00 & 0,00 \\
\hline ROA & 1069 & $-0,04$ & 1,46 & 0,57 & $-46,67$ \\
\hline VOL & 947 & 36,19 & 22,18 & 236,54 & 4,04 \\
\hline CRESC & 930 & 0,20 & 0,80 & 17,55 & $-1,71$ \\
\hline MTB & 1066 & 1,26 & 3,74 & 71,00 & 0,02 \\
\hline TAM & 1069 & 8,37 & 1,85 & 14,16 & 0,00 \\
\hline
\end{tabular}

Fonte: Dados da pesquisa

Já as medidas de desempenho e valor revelam que as empresas possuem, na média, um valor de mercado (MTB) 1,26 vezes superior ao valor contábil, uma rentabilidade do ativo (ROA) de -0,04, o que indica que as organizações geralmente apresentam prejuízo contábil e que esse prejuízo é cerca de $4 \%$ do ativo total e um crescimento médio no faturamento dos últimos três anos, correspondente a $20 \%$. Observa-se ainda que a volatilidade média foi de 36,19.

\subsection{Análise do relacionamento da compensação dos gestores com a sustentabilidade empresarial}

A Tabela 2 apresenta o resultado do modelo que estimou a relação entre a compensação dos gestores e a sustentabilidade empresarial. Buscou-se avaliar se, além das variáveis de performance propostas por Conyon e He (2011) e Funchal e Terra (2006), a variável sustentabilidade empresarial influencia na remuneração dos administradores.

Como resultados (Tabela 2), observa-se que houve relação significativa e positiva ao nível de 5\% entre as principais variáveis investigadas (compensação dos gestores e sustentabilidade empresarial), o que corrobora a hipótese $\mathrm{H}_{1}$ e sugere que as empresas mais sustentáveis tendem a possibilitar melhores remunerações a seus gestores. Em relação ao benefício plano de opção de compra de ações, observou-se significância também a 5\%, o que indica que as empresas que possuem esse tipo de benefício tendem a ter maiores remunerações totais dos executivos.

Ademais, foi observada relação negativa e significativa entre o risco total (volatilidade) e a remuneração total, indicando que as empresas com maior risco geralmente concedem menores remunerações a seus administradores. Nesse ponto, observa-se um resultado diferente dos autores Funchal e Terra (2006), pois eles não encontraram relação estatisticamente significativa do risco operacional (desvio padrão do ROA) com a remuneração executiva (Tabela 2). 
Tabela 2

Associação entre a compensação dos gestores e a sustentabilidade empresarial

\begin{tabular}{|c|c|}
\hline & RT \\
\hline \multirow[t]{2}{*}{ PO } & $0.3474 * *$ \\
\hline & $(0.1638)$ \\
\hline \multirow[t]{2}{*}{ BPL } & -0.1732 \\
\hline & $(0.3169)$ \\
\hline \multirow[t]{2}{*}{ BPE } & -0.0304 \\
\hline & $(0.1406)$ \\
\hline \multirow[t]{2}{*}{ ISE } & $0.2392 * *$ \\
\hline & $(0.1155)$ \\
\hline \multirow[t]{2}{*}{ NM } & $0.3210^{* *}$ \\
\hline & $(0.1617)$ \\
\hline \multirow[t]{2}{*}{ ROA } & -0.1580 \\
\hline & $(0.3821)$ \\
\hline \multirow[t]{2}{*}{ VOL } & $-0.0044 * *$ \\
\hline & $(0.0017)$ \\
\hline \multirow[t]{2}{*}{ CRESC } & -0.0343 \\
\hline & $(0.0284)$ \\
\hline \multirow[t]{2}{*}{ MTB } & $0.1038^{*}$ \\
\hline & $(0.0580)$ \\
\hline \multirow[t]{2}{*}{ TAM } & $0.3717 * * *$ \\
\hline & $(0.0927)$ \\
\hline \multirow[t]{2}{*}{ CONSTANTE } & $11.8900 * * *$ \\
\hline & $(0.8851)$ \\
\hline $\mathrm{N}$ & 811 \\
\hline R-sq & 0.094 \\
\hline adj. R-sq & 0.083 \\
\hline Rmse & 0.4017 \\
\hline T. Multicolinearidade & 1.36 \\
\hline T. Heter. de Baum (2001) & 0.0000 \\
\hline T. Autocorr. de Wooldridge (2002) & 0.0001 \\
\hline T. Hausman & 0.0000 \\
\hline
\end{tabular}

Notas: Os asteriscos indicam os níveis de significância: * $p<0,10$; ** $p<0,05$; e $* \star \star p<0,01$. O modelo foi estimado por Efeito Fixo. O teste de multicolinearidade revela que as variáveis não apresentam problemas de multicolinearidade. $O$ teste de heterocedasticidade de Baum (2001) rejeita a hipótese nula de variâncias homocedásticas. E o teste de Wooldridge (2002) rejeita a hipótese nula de ausência de autocorrelação.

Fonte: Dados da pesquisa 
Sobre o valor de mercado, notou-se significância estatística na relação do MTB com a remuneração total ao nível de 10\%, o que corrobora os estudos de Barontini e Bozzi (2008), Conyon e He (2011), Kaplan e Rauh (2008) e Kaplan (2012), indicando que os executivos tendem a ser pagos pela alta performance. Ressalta-se, ainda, que o tamanho da empresa também se mostrou relacionado positiva e significativamente ao nível de $1 \%$, o que sugere que empresas maiores tendem a oferecer melhores remunerações totais à diretoria, corroborando os trabalhos de Conyon e He (2011), Funchal e Terra (2006) e Correia, Amaral e Louvet (2014).

De maneira complementar, observou-se significância estatística de 5\% na relação entre a remuneração total e a qualidade da governança corporativa, medida pela variável NM, que avalia se as empresas estão ou não listadas no Novo Mercado da BM\&FBOVESPA. Essa constatação corrobora os autores Camargos e Helal (2007), Correia, Amaral e Louvet (2014), Farias (2012), Pinto e Leal (2013), Silva (2010), e Victor e Terra (2009), pois eles sugerem que a remuneração dos executivos pode ser justificada por instrumentos de Governança Corporativa.

\section{Conclusão}

O objetivo desta pesquisa foi investigar a influência da sustentabilidade empresarial na compensação dos gestores das empresas brasileiras não financeiras da BM\&FBOVESPA, no período de 2009 a 2013. O que fundamenta este estudo são a teoria de Agência, segundo a qual os gestores podem priorizar seus interesses em detrimento dos interesses das empresas, e a teoria dos Stakeholders, que sustenta que as empresas, para garantir valor em longo prazo, necessitaram conciliar os interesses dos acionistas com empregados, clientes, fornecedores e da comunidade.

A preocupação com o alinhamento dos interesses do principal e do agente tem sido evidenciada na literatura e sabe-se que uma das formas de alinhar esses interesses é oferecer aos gestores mecanismos de incentivo, os quais são traduzidos em salário-base, planos de bônus anuais, plano de opção de compra de ações, entre outros.

Os temas Governança Corporativa e Sustentabilidade Empresarial, como discutido anteriormente, abrangem um grande volume de pesquisas isoladas, mas poucas delas focam na interação entre esses dois temas. Não foram encontrados, na literatura nacional nem na internacional, estudos empíricos sobre esses dois constructos - Governança e Sustentabilidade. Especificamente, a relação entre sustentabilidade empresarial e compensação dos gestores também não foi observada sob o enfoque teórico o que mostra um diferencial deste trabalho.

Em relação à metodologia desta pesquisa, procedeu-se à análise da estatística descritiva das variáveis utilizadas no estudo e aplicou-se o método de regressão com dados em painel para testar a relação proposta. A análise descritiva revelou que em média a remuneração total dos gestores é de $\mathrm{R} \$ 8,48$ milhões, cerca de $13 \%$ da amostra envolve empresas listadas no ISE da BM\&FBOVESPA e $49 \%$ fazem parte do Novo Mercado. Ademais, as empresas possuem, em média, um valor de mercado 1,26 vezes superior ao valor contábil, uma rentabilidade do ativo negativa de cerca de $4 \%$, um crescimento médio no faturamento dos últimos três anos correspondente a $20 \%$ e volatilidade de 36,19 no período investigado.

No tocante aos resultados dos modelos de regressão em painel, observou-se uma relação positiva e estatisticamente significativa ao nível de $5 \%$ entre as variáveis de interesse. Assim, infere-se que as empresas listadas no ISE da BM\&FBOVESPA tendem a conceder maiores remunerações totais a seus gestores. Além disso, observou-se relação negativa da volatilidade com a remuneração total dos gestores, o que indica que as empresas que possuem maiores riscos tendem a oferecer menores remunerações totais a seus executivos.

De maneira complementar, notou-se que as empresas maiores geralmente concedem melhores remunerações a seus gestores, o que corrobora os estudos de Conyon e He (2011), Funchal e Terra (2006) e Correia, Amaral e Louvet (2014). 
Destaca-se ainda que foi observada relação positiva e estatisticamente significativa a $10 \%$ da remuneração total com o valor de mercado (MTB). Desse modo, sugere-se que os executivos geralmente são pagos pela alta performance, assim como observado nos estudos de Barontini e Bozzi (2008), Conyon e He (2011), Kaplan e Rauh (2008) e Kaplan (2012).

Esta pesquisa contribuiu com a literatura sobre a Compensação dos Gestores e Sustentabilidade Empresarial, não só por envolver dois temas relevantes da literatura, mas também por mostrar que as empresas listadas no ISE tendem a remunerar melhor seus executivos, o que indica que as organizações que se preocupam com a geração e valor em longo prazo, tendem a buscar também a mitigação dos conflitos de interesses entre acionistas e gestores, por meio de maiores compensações aos gestores.

Como sugestões para pesquisas futuras, pode-se avaliar como os outros mecanismos de governança corporativa afetam a compensação dos gestores, bem como construir um indicador de sustentabilidade e testar a relação desse indicador com a remuneração total dos administradores.

\section{Referências}

Alves, D. L. (2008). Sustentabilidade: estado da arte e um estudo de evento sobre o indice de sustentabilidade empresarial, Dissertação de Mestrado em Administração, Faculdade de Gestão e Negócios, Universidade Federal de Uberlândia, Uberlândia, MG, Brasil, $143 f$.

Andrade, M. M. (2001). Como preparar trabalhos para cursos de pós-graduação: noções práticas. $4^{\mathrm{a}}$ ed. São Paulo: Atlas.

Balafas, N., \& Florackis, C. (2013). CEO compensation and future shareholder returns: Evidence from the London Stock Exchange. Journal of Empirical Finance, 27 (1), pp. 97-115. DOI: http://dx.doi. org/10.1016/j.jempfin.2013.10.011

Barontini, R., \& Bozzi, S. (2008). Executive compensation and ownership structure: Empirical evidence for Italian listed companies. Recuperado em 7 de março, 2014, em: http://www.efmaefm.org/EFMAMeetings/Efma Annual Meetings/2008-athens/Bozzi.pdf.

Beato, R. S., Souza, M. T. S., \& Parisotto, I. R. S. (2009). Rentabilidade dos índices de sustentabilidade empresarial em bolsas de valores: um estudo sobre o ISE/Bovespa. Revista de Administração e Inovação - RAI, 6(3), pp. 108-127. DOI: http://dx.doi.org/10.5585/rai.v6i3.472

Beuren, I. M., Beck, F., \& Silva, J. O. (2012). Remuneração variável dos empregados versus aspectos organizacionais das maiores sociedades anônimas do Brasil. Revista Economia \& Gestão da PUC Minas, 12(29), pp. 1-15. DOI: http://dx.doi.org/10.5752/P.1984-6606.2012V12N29P51

BM\&FBovespa. (2014). Livro do ISE. Recuperado em 7 de março, 2014, em: http://www.isebvmf.com.br.

BM\&FBovespa. (2014). Níveis Diferenciados de Governança Corporativa. Recuperado em 7 de março, 2014, em: http://www.bmfbovespa.com.br.

Breusch, T., \& Pagan, A. (1980). The Lagrange Multiplier Test and its Applications to Model Specification in Econometrics. The Review of Economic Studies, 47(1), pp. 239-253.

Camargos, M. \& Helal, D. (2007). Remuneração executiva, desempenho econômico-financeiro e a estrutura de Governança Corporativa de empresas brasileiras. In: Encontro da Associação Nacional de Pós-Graduação e Pesquisa em Administração (ENANPAD), 31, Rio de Janeiro, RJ, Brasil.

Carvalhal da Silva, A. L., \& Chien, A. C. Y. (2013). Remuneração Executiva, Valor e Desempenho das Empresas Brasileiras Listadas. Revista Brasileira de Finanças (Online), 11(4), pp. 481-502.

Carvalhal, A., \& Tavares, E. (2013). Does social responsability enhance firm value and return in Brazil? Corporate Ownership \& Control, 10(2), pp. 253-258. 
Cavalcanti, J., \& Boente, D. (2012). A Relação de Risco e Retorno nas Empresas Integrantes do Índice de Sustentabilidade Empresarial no Período de 2008 a 2010. Revista Ambiente Contábil, 4(1), pp. 51-71.

Comissão de Valores Mobiliários. (2014). Legislação e Regulamentação CVM. Recuperado em 7 de março, 2014 de http://www.cvm.gov.br/.

Conyon, M., \& He, L. (2011). Executive compensation and corporate governance in China. Journal of Corporate Finance. Recuperado em 7 de março, 2014 de: http://www.sciencedirect.com/science/ article/pii/S0929119911000472.

Correia, L. F. (2008). Um Índice de Governança para Empresas no Brasil. 274 f. Tese, Doutorado em Administração, Centro de Pós-Graduação e Pesquisa em Administração, Faculdade de Ciências Econômicas, Universidade Federal de Minas Gerais (CEPEAD-FACE-UFMG), Belo Horizonte, MG, Brasil.

Correia, L. F., Amaral, F. H., \& Louvet, P. (2014). Remuneração, Composição do Conselho de Administração e Estrutura de Propriedade: Evidências Empíricas do Mercado Acionário Brasileiro. Advances in Scientific and Applied Accounting, 7(1), pp. 2-37.

Dalmacio, F. Z., Rezende, A. J., \& Slomski, V. (2009). Análise setorial das medidas de performance utilizadas nos contratos de remuneração dos gestores. Revista Universo Contábil, 5(3).

Elkington, J. (2001). Canibais com garfo e faca. Makron Books.

Espejo, R. A. (2008). Análise do Risco das Ações Negociadas na BMßFBovespa na Crise de 2008 segundo o ISE e os NDGC. 110 f. Dissertação de Mestrado em Contabilidade, Programa de Pós-Graduação em Contabilidade, Setor Ciências Sociais Aplicadas, Universidade Federal do Paraná, Curitiba, PR, Brasil.

Farias, K. T. R. (2012). Mecanismos de controle do reporting financeiro das companhias abertas do Brasil. 192 f. Tese, Doutorado em Ciências Contábeis, Departamento de Contabilidade e Atuária da Faculdade de Economia, Administração e Contabilidade da Universidade de São Paulo, São Paulo, SP, Brasil.

Fávero, L. P., Belfiore, P., Silva, F. L., \& Chan, B. L. (2009). Análise de dados: modelagem multivariada para tomada de decisões. Rio de Janeiro: Elsevier.

Freeman, R. E., \& McVea, J. (2001). A Stakeholder Approach to Strategic Management. Recuperado em 7 de março, 2014 de http://ssrn.com/abstract=263511.

Funchal, J. A., \& Terra, P. R. S. (2006). Remuneração de Executivos, Desempenho Econômico e Governança Corporativa: um Estudo Empírico em Empresas Latino-Americanas. Encontro da Associação Nacional de Pós-Graduação e Pesquisa em Administração (ENANPAD), 30, Salvador, BA, Brasil.

Garcia, A. S. \& Orsato, R. J. (2013). Índices de sustentabilidade empresarial: porque participar? Encontro da Associação Nacional de Pós-Graduação e Pesquisa em Administração (ENANPAD), 37, Rio de Janeiro, RJ, Brasil.

Gil, A. C. (1991). Como elaborar projetos de pesquisas. São Paulo, Atlas.

Greene, W. H. (2002). Econometric Analysis. New Jersey: Pearson Education, Prentice Hall.

Gujarati, D. N., \& Porter, D. C. (2011). Econometria Básica. 5ª ed. Porto Alegre: AMGH.

Heij, C., Boer, P., Franses, P. H., Kloek, T., \& Van Dijk, H. K. (2004). Econometric Methods with Applications in Business and Economics. New York: Oxford University Press.

Henderson, H. (2007). Mercado Ético: A Força do Novo Paradigma Empresarial. São Paulo, Cultrix.

Holanda, A., \& Mapurunga, P. (2012). Disclosure social e reputação corporativa: um estudo das empresas listadas no índice de sustentabilidade empresarial da BM\&FBOVESPA. Revista Uniabeu, 5(11), pp. 91-107. 
Instituto Brasileiro de Governança Corporativa. (2009). Código de Melhores Práticas de Governança Corporativa. 4. ed., São Paulo: IBGC.

Índice de Sustentabilidade Empresarial - ISE. (2010). Relatórios gerais. Recuperado em 07 de março de 2014 de: http://www.isebvmf.com.br/.

Jensen, M. C., \& Meckling, W. (1976). Theory of the firm: managerial behavior, agency costs and capital structure. Journal of Financial Economics. 3(4), pp. 305-360. DOI: http://dx.doi.org/10.1016/0304$-405 \mathrm{X}(76) 90026-\mathrm{X}$

Jensen, M. (2001). Value Maximization, Stakeholder Theory, and the Corporate Objective Function. Journal of Applied Corporate Finance. 14(3), pp. 8-21.

Jensen, M., \& Murphy, K. (1990). Performance pay and top-management incentives. Journal of Political Economy, 98(2), pp. 225-264.

Kaplan, S. (2012). Executive compensation and corporate governance in the US: perceptions, facts and challenges. National Bureau of Economic Research. Recuperado em 7 de março, 2014 de: http://ssrn. com/abstract $=2134208$.

Kaplan, S., \& Rauh, J. (2009). Wall Street and Main Street: What contributes to the rise in the highest incomes? NBER Working Paper. Recuperado em 7 de março, 2014 de: http://www.nber.org/papers/ w13270. DOI: http://dx.doi.org/10.3386/w13270

Kennedy, P. (2009). Manual de Econometria. Rio de Janeiro: Campus Elsevier.

Krauter, E. (2013). Remuneração de Executivos e Desempenho Financeiro: Um Estudo com Empresas Brasileiras. Revista de Educação e Pesquisa em Contabilidade, 7(3), pp. 259-273. DOI: http://dx.doi. org/10.17524/repec.v7i3.988

Krechovská, M., \& Procházková, P. T. (2014). Sustainability and its Integration into Corporate Governance Focusing on Corporate Performance Management and Reporting. Procedia Engineering, 69(1), pp. 1144-1151. DOI: http://dx.doi.org/10.1016/j.proeng.2014.03.103

Lameira, V. J., Ness Jr., W, L., Quelhas, O, L, G., \& Pereira, R, G. (2013). Sustainability, Value, Performance and Risk in the Brazilian Capital Markets. Revista Brasileira de Gestão e Negócios, 15(46), pp. 76-90. DOI: http://dx.doi.org/10.7819/rbgn.v15i46.1302

Machado, M. R., Machado, M. A. V., \& Corrar, L. J. (2009). Desempenho do índice de sustentabilidade empresarial (ISE) da Bolsa de Valores de São Paulo. Revista Universo Contábil, 5(2), pp. 24-38.

Martins, G. A., \& Theóphilo, C. R. (2009). Metodologia da investigação científica para ciências sociais aplicadas. $2^{a}$ ed. São Paulo: Atlas.

Mason, C., \& Simmons, J. (2014). Embedding Corporate Social Responsibility in Corporate Governance: A Stakeholder Systems Approach. Journal of Business Ethics, 119(1), pp. 77-86. DOI: http://dx.doi. org/10.1007/s10551-012-1615-9

Milani Filho, M. (2008). Responsabilidade social e investimento social privado: entre o discurso e a evidenciação. Revista de Contabilidade \& Finanças, 19(47), pp. 89-101.

Murphy, K. J. (1998). Executive Compensation. Recuperado em 7 de março, 2014 de: http://ssrn.com/abstract $=163914$.

Nagar, A. L. \& Basu, S. R. (2002). Weighting socio-economic indicators of human development: a latente variable approach. In: ULLAH et al. (org.). Handbook of applied econometrics and statistical inference. New York: Marcel Dekker.

Nunes, J. G., Teixeira, A. J. C., Nossa, V., \& Galdi, F. C. (2010). Análise das variáveis que influenciam a adesão de empresas ao índice BM\&FBovespa de sustentabilidade empresarial. Revista de Administração e Contabilidade da Unisinos, 7(4), pp. 15-30. 
Organization for Economic Co-Operation and Devolopment. (2004). OECD Principles of Corporate Governance. Paris: OECD.

Peixoto, F. M. (2012). Governança corporativa, desempenho, valor e risco: estudo das mudanças em momentos de crise. $216 \mathrm{f}$. Tese de Doutorado em Administração, Universidade Federal de Minas Gerais (UFMG), Belo Horizonte, MG, Brasil.

Perobelli, F., Lopes, B. de S., \& Silveira, A. D. M. (2012). Planos de opções de compra de ações e o valor das companhias brasileiras. Revista Brasileira de Finanças, 10(1), pp. 105-147.

Pinto, M. B., \& Leal, R. P. C. (2013). Ownership Concentration, Top Management and Board Compensation. RAC - Revista de Administração Contemporânea, 17(3), pp. 304-324. DOI: http://dx.doi. org/10.1590/S1415-65552013000300004

Ricart, J. E., Rodriguez, M. A., \& Sanchez, P. (2005). Sustainability in the boardroom: An Empirical examination of Dow Jones Sustainability World Index leaders. Corporate Governance. 5(3), pp.24-41.

Rossi Jr., J, L. (2009). What is the Value of Corporate Social Responsibility? An Answer from the Brazilian Sustainability Index. Recuperado em 7 de março, 2014 de http://ssrn.com/abstract=1338114.

Sampaio, M. N. L. (2009). Governança Corporativa e Remuneração de Executivos no Brasil. 33 f. Dissertação de Mestrado em Administração, Instituto COPPEAD de Administração da Universidade Federal do Rio de Janeiro, Rio de Janeiro, RJ, Brasil.

Santos, A. R. (2002). Metodologia científica: a construção do conhecimento. $4^{\text {a }}$ ed. Rio de Janeiro: DP\&AB.

Silva, P. C. C. (2010). Transparência de Remuneração de Executivos e Governança Corporativa no Brasil. 32 f. Dissertação de Mestrado em Finanças e Economia Empresarial, Escola de Pós-Graduação em Economia da Fundação Getúlio Vargas, Rio de Janeiro, RJ, Brasil.

Silveira, A. D. M. (2004). Governança Corporativa e Estrutura de Propriedade: determinantes e relação com o desempenho das empresas no Brasil. 250 f. Tese de Doutorado em Administração, Faculdade de Economia, Administração e Contabilidade da Universidade de São Paulo, FEA-USP, São Paulo, SP, Brasil.

Silveira, A. D. M., Yoshinaga, C. E., \& Borba, P. R. F. (2005). Crítica à teoria dos stakeholders como função-objetivo corporativa. Caderno de Pesquisas em Administração. 12(1), pp. 33-42.

Sonza, I. B. (2012). Eficiência em estruturas de propriedade concentradas e compensação de executivos: novas evidências para o Brasil. 326f. Tese de Doutorado em Administração, Universidade Federal do Rio Grande do Sul, Escola de Administração, Rio Grande do Sul, RS, Brasil.

Sprague, R. (2010). Beyond shareholder value: Normative standards for sustainable corporate governance. Wm. \& Mary Bus. L. Rev., 1(1), pp. 47-82.

Suherman H., Rahmawati, W., \& Buchdadi, A. D. (2011). Firm Performance, Corporate Governance, and Executive Compensation in Financial Firms: Evidence from Indonesia. 1(1), pp. 1-10.

Teixeira, E. A., Nossa, V., \& Funchal, B. (2011). O índice de sustentabilidade empresarial (ISE) e os impactos no endividamento e na percepção do risco. Revista Contabilidade e Finanças (USP), 22(55), pp. 29-44. DOI: http://dx.doi.org/10.1590/S1519-70772011000100003

Victor, F., \& Terra, P. (2009). Determinantes do nível de evidenciação da remuneração por meio de opções de ações no Brasil. Encontro da Associação Nacional de Pós-Graduação e Pesquisa em Administração, 33. São Paulo, SP, Brasil.

Vital, J. T., Cavalcanti, M. M., Dallo, S., Moritz, G. O., \& Costa, A. M. (2009). A influência da participação no Índice de Sustentabilidade Empresarial (ISE) no Desempenho Financeiro das empresas. Revista de Ciências da Administração, 11(24), pp. 11-40. DOI: http://dx.doi.org/10.5007/2175$-8077.2009 \mathrm{v} 11 \mathrm{n} 24 \mathrm{p} 11$ 
Wong, S. C. Y. (2009). Uses and Limits of Conventional Corporate Governance Instruments: Analysis and Guidance for Reform (Integrated version). Private Sector Opinion, Global Corporate Governance Forum. Recuperado em 7 de março, 2014 de: http://ssrn.com/abstract=1409370.

Wooldridge, J. M. (2002). Econometric Analysis of Cross Section and Panel Data. London: MIT Press. 